\title{
Language profiles and mental health problems in children with specific language imapirment and children with AD/HD
}

\author{
Wenche Andersen Helland, Turid Helland and Mikael Heimann
}

\section{Linköping University Post Print}

\section{Tweet}

N.B.: When citing this work, cite the original article.

Original Publication:

Wenche Andersen Helland, Turid Helland and Mikael Heimann, Language profiles and mental health problems in children with specific language imapirment and children with AD/HD, 2014, Journal of Attention Disorders, (18), 3, 226-235.

http://dx.doi.org/10.1177/1087054712441705

Copyright: SAGE Publications (UK and US)

http://www.uk.sagepub.com/home.nav

Postprint available at: Linköping University Electronic Press

http://urn.kb.se/resolve?urn=urn:nbn:se:liu:diva-77386 
Abstract

Objective: This study aimed to explore whether children with specific language impairment and children with AD/HD can be differentiated from each other in terms of their language profiles, and also to investigate whether these two clinical groups differ regarding mental health problems.

Method: Fifty-nine children in the age range 6-12 years participated in the study. The parents completed the Children's Communication Checklist Second Edition and the Strengths and Difficulties Questionnaire.

Results: Communication impairments were as prominent in the AD/HD group as in the SLI group, however the groups were separable from each other in terms of their language profiles. Furthermore, the AD/HD group experienced significantly more mental health problems compared to the SLI group

Conclusion: Language should be assessed in children with AD/HD and instruments sensitive to AD/HD should be included when assessing children with SLI. Mental health should be an area of concern to be addressed in both groups. 
Language profiles and mental health problems in children with specific language impairment and children with $\mathrm{AD} / \mathrm{HD}$

Specific language impairment (SLI) is a term commonly used to describe a condition where a child with otherwise typical development demonstrates significant limitations in expressive and/or receptive language abilities (Leonard, 1998). Despite the lack of a "gold standard" for a diagnosis of SLI, mismatch between actual and expected language skills on one hand and verbal and non-verbal skills on the other hand, is often used to identify the condition (Bishop \& McDonald, 2009; Leonard, 1998).

Roughly estimated prevalence of SLI is considered to be $7 \%$ of the general population (Tomblin et al., 1997). Children diagnosed with SLI are a rather heterogeneous group but difficulties mastering language structure (grammar, phonology) and content (vocabulary) are prominent findings (Whitehouse, Line, Watt, \& Bishop, 2009). Furthermore, children with SLI often experience reading and writing disorders (Stackhouse, 2000) although these disorders can also be present in the absence of language difficulties. These children might also encounter pragmatic language impairments, which means that they may have problems with appropriate use and interpretation of language in a given context (Adams, 2008; Whitehouse et al., 2009). These difficulties are often regarded as secondary to the structural problems. Thus, if a child is unable to speak intelligibly or find the right words, communication with other people might break down. However, pragmatic language impairments might also be present in the absence of structural language problems (Adams \& Lloyd, 2005; Geurts \& Embrechts, 2008). Some controversy exists whether "specific language impairment" in fact is "specific" or rather a marker of more complex neurodevelopmental or neuropsychiatric disorders in the child (Gillberg, 2010; Miniscalo, Nygren, Hagberg, Kadesjø, \& Gillberg, 2006; Norbury, Tomblin, \& Bishop, 2008). 
$\mathrm{AD} / \mathrm{HD}$ is the most frequent diagnosed neuropsychiatric disorder in childhood with a reported prevalence rate of about 3-5 \% (Hulme \& Snowling, 2009; LaForette, Murray, \& Kollins, 2008). The disorder affects the child's ability to control attention and behaviour in an optimal manner and it often occurs together with impulsivity and over-activity (Hume \& Snowling, 2009). The consequence is often behaviour with a negative effect on social and academic interaction. For some children also their language development may be compromised (Redmond, Thompson, \& Goldstein, 2011).

$\mathrm{AD} / \mathrm{HD}$ is the most frequent psychiatric diagnosis given to children with language impairments (Miniscalco et al., 2006; Snowling, Bishop, Stothard, Chipchase and Kaplan, 2006; Tirosh \& Cohen, 1998). Conversely; a significant proportion of children with $\mathrm{AD} / \mathrm{HD}$ has been found to present with concomitant language impairments, including reading and writing disorders (Bignell \& Chain, 2007; Bruce, Thernlund and Nettelbladt, 2006; Cross, 2011; Helland, Biringer, Helland, \& Heimann, 2010; Toplak, Rucklidge, Hetherington, John, \& Tannock, 2003; Åsberg, Kopp, Berg-Kelly; \& Gillberg, 2010). Criteria for defining language impairments differ across studies, with a reported overlap varying between $35 \%$ and $90 \%$ (Lou \& Timler, 2008). Although these two common disorders frequently co-occur, studies exploring language abilities of children with ADHD or directly comparing these two high-incidence populations are relatively few (McInnes, Humphries, Hogg-Johnson, \& Tannock, 2003; Redmond et al., 2011). Furthermore, in clinical contexts language related problems are seldom screened for as part of the assessment procedure for AD/HD. Likewise, mental health problems are commonly not assessed in children with SLI (Im-Bolter \& Cohen, 2007).

Pragmatic language impairments have been observed in children within a broad range of developmental disorders, including children with SLI and children with AD/HD (Bishop, 1998; Bishop \& Baird, 2001; Helland \& Heimann, 2007; Helland et al., 2010) 
and for some children this is indeed the most overt part of their communicative problems (Adams, 2008). When looking at the specific symptoms of AD/HD, Im -Bolter and Cohen (2007) argued that potential overlap between pragmatic skills and language processing skills may be symptoms of hyperactivity. The children may often show pragmatic problems by "talking incessantly" and "interrupting others", inattention by "not following through on instructions" or "not listen when spoken to". According to Cohen and colleagues (2000) systematic language assessment is rarely completed in children with $\mathrm{AD} / \mathrm{HD}$. They argue that a possible reason for this is that the potential language deficits are primarily to be found in the area of pragmatics which is not so readily assessed by standardized tests. This motivating a direct comparison of pragmatic and structural language abilities in children with $\mathrm{AD} / \mathrm{HD}$ and children with SLI, as presented in the current study.

It is generally well acknowledged that poor language skills and emotional and behavioural problems, including psychiatric disorders, are closely interconnected, and many children with SLI present with similar problems to what is seen in children with AD/HD (Mackie \& Law, 2010; Nelson, Benner, \& Cheney, 2005). Thus, many of the symptoms characterizing psychiatric disorders could be considered indicative of SLI just as well (Im-Bolter \& Cohen, 2007). In a longitudinal Canadian study, Beitchman and colleagues (2001) found that in a group of young adults diagnosed with language impairment in early childhood, $40 \%$ were diagnosed with a psychiatric disorder at age 19. Furthermore, Beitchman, Brownlie, and Wilson (1996) argued that psychiatric disorders are as common in language impaired populations as language impairments are in psychiatric populations. Recently, Gillberg (2010) claimed that co-existence of disorders and sharing of symptoms across disorders is the rule rather than the exception in the area of child psychiatry and developmental medicine. 
It has been suggested that the social difficulties experienced by many children with AD/HD may be caused by language deficits and that their poor pragmatic language skills may make them especially vulnerable to disruption (Camarata \& Gibson, 1999). As the forming and maintenance of friendships, which may contribute to healthy psychosocial development, are largely dependent on language proficiencies, children with limited language skills might experience poor peer acceptance and be left on the outskirts of social activity (Bruce et al., 2006; Will \& Coufal, 2005). Thus language impairments may generally influence children's psychosocial development in a negative direction (Antoniazzi, Snow, \& Dickson-Swift, 2010).

Considering the substantial overlap of symptoms reported in children with SLI and children with $\mathrm{AD} / \mathrm{HD}$, the first aim of the present study was to explore whether these two clinical groups can be differentiated from each other, as well as from a group of typically developing children in terms of their language profiles. As most accounts of SLI emphasise the difficulties these children have with language structure, we hypothesized that children wit $\mathrm{AD} / \mathrm{HD}$ and children with SLI would differ regarding their language profiles. The second aim was to investigate whether children with SLI differ from children with $\mathrm{AD} / \mathrm{HD}$ regarding mental health problems. Due to problem behaviours commonly reported in children with $\mathrm{AD} / \mathrm{HD}$ we hypothesized that more metal health problems would be revealed in the ADHD group than in the SLI group.

\section{Method}

\section{Participants and procedure}

Two clinical groups: a SLI group and an AD/HD group and one group of typically developing children (TD) in the age range 6 to 12 years participated in this study $(n=59)$. The SLI group consisted of 19 children (mean age=8.7, SD=2.2; 17 boys). A letter of information, a letter of informed consent, a copy of the Children's Communication Checklist 
Second Edition (CCC-2; Bishop, 2003) and a copy of the Strengths and Difficulties Questionnaire (SDQ; Goodman, 1999) were sent to the parents of children registered at a Norwegian support system for special education. Children meeting the following criteria were included in the study: a clinical diagnosis of SLI by a speech and language therapist, no mental retardation, Norwegian as their first language, no sensory neural hearing loss, speaking in sentences and consistently completed CCC-2 as specified in the manual (Bishop, 2003).

The AD/HD group consisted of 21 children (mean age $=10.1 ; \mathrm{SD}=1.8 ; 17$ boys). In a former study (Helland et al., 2010) a group of 28 children with AD/HD aged 6-15 years was investigated. This was a combined sample requited from an outpatient clinic, a Norwegian support system for special education and a parent support group for ADHD. Through these institutions a letter of information, a letter of informed consent, a copy of the CCC-2 and a copy of the SDQ to fill out were sent to the patents. A closer description is presented in Helland et al. (2010). In order to create a group with the same age range as the SLI group, those older than 12 years in the study described were excluded and the remaining 21 children (aged 6-12 years) formed the AD/HD group in the present study. The children all met the following criteria: a diagnosis of $\mathrm{AD} / \mathrm{HD}$ as reported by parents, no mental retardation according to parental reports, Norwegian as their first language, no sensory neural hearing loss and the ability to speak in sentences. Also, the questionnaires should be consistently completed. As can bee seen, the SLI group was somewhat younger than the AD/HD group. In order to investigate a possible impact of the age differences a correlation analysis between age and language scores was run, but no significant correlations were found, this supporting the comparison of the two groups.

To serve as a comparison group 19 typically developing (TD) children were selected from a sample $(\mathrm{n}=108)$ of children aged 6-12 years who took part in a former validation study of the Norwegian adaptation of the CCC-2 (Helland, Biringer, Helland, \& Heimann, 2009). 
These children did not have any known learning disabilities or special education needs, nor did they have any problems regarding language or communication as reported by their parents. For each SLI child a TD child of same age and gender was randomly drawn from this sample. Thus the TD group consisted of 19 children of same mean age and same distribution of girls and boys as the SLI group.

The study was conducted in accordance with the Helsinki Declaration of the World Medical Association Assembly and approved by the Regional Committee for Medical and Health Research Ethics, University of Bergen.

Assessment tools

The Children's Communication Checklist, Second Edition (CCC-2)

The CCC-2 (Bishop, 2003; Norwegian adaptation: Helland \& Møllerhaug, 2006) is a checklist designed to distinguish children with communication impairments from typically developing children as well as to identify pragmatic language impairments in children with communication problems. The CCC-2 consists of 70 items grouped into 10 subscales (See Table 1). The separate subscales includes items assessing, for example, whether the child leaves off beginnings or ends of words (A. Speech), leaves off past tense -ed endings of words (B. Syntax), mixes up words of similar meaning (C. Semantics), explains a past event clearly (D. Coherence), asks questions even though already knowing the answer (E. Inappropriate initiation), uses favorite phrases in inappropriate contexts (F. Stereotyped language), appreciates humor expressed by irony (G. Use of context), looks at the person he is talking to (H. Nonverbal communication), hurts or upsets other children unintentionally (I. Social relations) or shows interests in things or activities most people would find unusual, i.e. washing machines or traffic lights (J. Interests). The respondents are asked to indicate the frequency of the communicative behaviours described on a four point scale, a high raw score indicating poorer performance. Four scales measure structural aspects of language, four scales 
measure pragmatic aspects of language and two scales measure non-linguistic behaviours that are commonly found in cases of autistic disorders. An overall measure of communication skills, the General Communication Composite (GCC), effective at discriminating children with communication impairments from typically developing children, is derived by summing the scaled scores of the eight first subscales. Based on previous findings using the CCC-2 in a Norwegian sample (Helland et al., 2009), cut-off at or below 64 scaled scores was selected. The Social Interaction Deviance Composite (SIDC) is designed to identify children with pragmatic impairments disproportionate to their abilities relating to language structure. A negative SIDC score is indicative of social interaction difficulties disproportionate to the child's general level of communication. However, this composite should only be interpreted in cases where the child also scores below cut-off on the GCC, unless the score is -15 or less (Bishop, 2003). Although not included as a part of the CCC-2, several studies (Bignell \& Chain, 2007; Geurts \& Embrechts, 2008) have reported that a general pragmatic composite (PC) may be calculated by summing the scaled scores of scales D, E, F, G, H, and in the present study the PC was computed. Bishop (2003) reports internal consistency values for the CCC-2 ranging from .66 to .80 in the British standardization sample $(n=542)$, and inter-rater reliability between parents and teachers in a clinical sample ranged from .16 to $.79(n=55)$. For the Norwegian adaptation of the CCC-2, Helland and colleagues (2009) report internal consistency (Chronbach's alpha) values between .73 and .89. and inter-rater reliability ranging from .44 to .76 . The CCC-2 is scored by an automated scoring program which also includes a consistency check indicating if the respondents have understood how to rate the questionnaire. For a detailed description of the CCC-2 and the Norwegian adaptation process see Helland and colleagues (2009). Strengths and Difficulties Questionnaire (SDQ) 
For the clinical groups, parents also completed the SDQ (Goodman, 1999). The SDQ is a brief behavioural screening questionnaire for children aged 4-16 years, extensively validated in various countries (Muris, Meesters, \& van den Berg, 2003). The questionnaire has been translated into the different Nordic languages, including Norwegian (Obel et al., 2004), and it is available online (sdqinfo.org). The questionnaire consists of 25 items, describing positive and negative attributes of children, divided into five subscales of five items each; measuring emotional symptoms, conduct problems, hyperactivity-inattention problems, peer problems and pro-social behaviour. By combining the first four subscale scores a total difficulty score is computed. An impact supplement assesses the overall problem severity, distress to the child and the family and interference with everyday life. The subscales are scored on a three point scale: "not true", "somewhat true" or "certainly true". Each subscale score ranging from 0-10 and the total difficulties score ranging from 0-40. Depending on the scores obtained, the child may be classified categorically as "normal", "borderline" or "abnormal" according to the scoring instructions. In the present study the "borderline" and "abnormal" categories are combined and presented as one category "borderline/abnormal". Cut-off scores for "borderline/abnormal" scores are as follows; Total difficulties score 14 or more, emotional symptoms 4 or more, conduct problems 3 or more, hyperactivity-inattention 6 or more, peer problems 3 or more, prosocial behaviour 5 or less (this scale is inverted), and impact 1 or more. Separate versions of the questionnaire are available for parents, teachers and children. In the present study the parent version was used. Internal consistency values (Cronbach's alpahas) for the various SDQ scales are satisfactory with mean alpha .70 for the parent version and test-restest stability showed intraclass correlations coefficients well in the .70 range or higher.(Muris, Meesters, \& van den Berg, 2003).

Statistical Analyses 
On the CCC-2 group differences were analyzed using one-way analysis of variance (ANOVA) with groups (three levels) as a between factor and post hoc comparisons were conducted using Tukey's honestly significant difference (HSD) test. On the SDQ, group differences between the two clinical groups were tested non-parametrically, using the MannWhitney U-test, due to non-normal distribution of scores within groups. Tests were two-tailed with an alpha level of 0.05 as planned comparisons were conducted. The statistical analyses were performed using SPSS version 18.0. Regarding calculation of effect sizes, $\eta 2$ is reported comparing three groups (CCC-2), and Cohens's $d$ is reported when two groups are compared (SDQ). General guidelines for interpreting these values are that a $d$ of .20 is considered small, a $d$ of .50 is considered moderate and a $d$ of .80 is considered large (Cohen, 1988).

\section{Results}

\section{Language and communication measures, CCC-2}

A total of 17 out of 21 children (80.9\%) in the AD/HD group and 15 out of 19 children $(78.9 \%)$ in the SLI group were identified as having clinically significant communication impairments based on the GCC. The corresponding proportion in the TD group was 2 out of 19 children (10.5\%). On the SIDC 12 of the 21 children $(57.1 \%)$ in the $\mathrm{AD} / \mathrm{HD}$ group obtained a negative score indicating that pragmatic aspects of communication were disproportionate impaired relative to language structure (one child had a SIDC of less than -15 with GCC within normal limits). In the SLI group one child (5.3\%) and in the TD group two children $(10.5 \%)$ obtained a negative score.

* Table 1 in about here *

\section{CCC-2 scales}

The one -way ANOVAs comparing the means of the three groups on the 10 separate CCC-2 scales all revealed significant main effects of group with all $p s<.05$. As is evident from Table 1, post hoc tests showed that the TD group outperformed the clinical groups on all 
CCC-2 scales (all $p$ s <. 05). The effect sizes were quite strong, with $\eta^{2}$ between .14 and .54 .

The SLI group scored significantly higher (more impaired) than the AD/HD group and the TD group on the speech- and the syntax scale; both measuring structural aspects of language. No differences were found between the AD/HD group and the TD children on these scales. On the interests scale the AD/HD group scored significantly higher than the SLI group and the TD group, whereas no difference was found between the SLI group and the TD group. No differences were found on the remaining seven scales between the AD/HD group and the SLI group. However, on all of these scales the clinical groups scored significantly higher than the TD group.

\section{CCC-2 Composite scores}

When the General Communication Composite (GCC), the Pragmatic Composite (PC) and the Social Interactional Deviance Composite (SIDC) were used as dependant measures, there was also a main effect of group (all $p s<.01$ ). Post hoc tests revealed no differences between the AD/HD group and the SLI group on the two first composites but TD group outperformed the clinical groups. On the SIDC the SLI group differed significantly from the AD/HD group and the TD group by showing most impairment related to language structure.

\section{Mental health problems}

$S D Q$ scores

As is evident from Table 2, the AD/HD group differed significantly (more impaired) from the SLI group on all problem scales as well as on the total difficulties score and the impact score on the SDQ ( $p<0.05$; Mann- Whitney $U$-test $)$. On the scale measuring pro-social behaviour no difference was found.

\footnotetext{
* Table 2 in about here *
} 
The effect sizes were large for emotional symptoms $(d=0.93)$, hyperactivityinattention $(d=1.45)$, total difficulties $(d=1.25)$ and impact $(d=0.81)$, moderate for conduct problems $(d=0.56)$ and peer problems $(d=0.70)$ and small for pro-social behaviour $(-0.23)$.

* Table 3 in about here *

As shown in Table 3 in the AD/HD group 19 children (90.5\%) scored in the abnormal/borderline range on the total difficulties score compared to 6 children $(31.6 \%)$ in the SLI group. On the impact scale the same was true for 18 children $(85.7 \%)$ in the AD/HD group and 10 children (52.6\%) in the SLI group. When inspecting the separate scales, the majority of children in the AD/HD group, not unexpectedly, scored in the abnormal/borderline range on the hyperactivity/ inattention problem scale $(85.7 \%)$, followed by the scales measuring emotional symptoms ( $81 \%)$, peer problems $(76.2 \%)$ and conduct problems (38.1\%). In the SLI group peer problems were most common $(57.8 \%)$, followed by hyperactivity/inattention problems (42.1\%), emotional symptoms $(31.6 \%)$ and conduct problems $(21.1 \%)$. Regarding the frequency of children scoring in the abnormal/borderline range, no significant differences were found between the SLI group and the AD/HD group on the scales measuring conduct problems, peer problems and pro-social behaviour.

\section{Discussion}

The current study had two specific aims; to explore whether children with SLI and children with $\mathrm{AD} / \mathrm{HD}$ can be differentiated from each other in terms of their language profiles and to investigate whether these two clinical groups differ regarding mental health problems. The main findings were that children with SLI and children with AD/HD were inseparable on an overall measure of communication but that they differed as to three out of 10 subscales on the CCC-2 as well as on the SIDC. In line with our hypothesis the AD/HD group was found to experience more mental health problems compared to the SLI group, although the latter also showed substantial impairments relative to norms. 
Almost $80 \%$ in both clinical groups were identified with communication problems. The majority of the children in the AD/HD group obtained a negative score on the SIDC, indicating a mismatch between pragmatic and structural aspects of language, whereas only one child in the SLI group showed a similar pattern. A positive SIDC score is typically found in children with SLI whereas a negative score is indicative of disproportionate pragmatic impairments (Bishop, 2003).

The CCC-2 profile showed that children with SLI differed from children with AD/HD on three scales: the speech scale, the syntax scale and the interests scale. On the speech and syntax scales, measuring language structure, the SLI group was significantly more impaired than the AD/HD group, which did not differ from the TD group, i.e. they simplified words by leaving out some sounds or they left out past tense endings. Difficulties mastering language structure are especially prominent in children with SLI and thus our results are in line with previous research (Im-Bolter \& Cohen, 2007; Whitehouse et al., 2009). On the scale measuring interests the SLI group performed equal to the TD group while the AD/HD group was significantly more impaired; tending for example to show interests in things or activities most people would find unusual or move the conversation to a favourite topic. Children with SLI seemed to adapt to new situations and react adequately in an unfamiliar situation to a greater degree compared to children with $\mathrm{AD} / \mathrm{HD}$. This may also explain why children with SLI show less mental health problems than children with AD/HD. An unexpected finding was that the $\mathrm{AD} / \mathrm{HD}$ group was as impaired as the SLI group on the scale measuring semantics, indicating that children with $\mathrm{AD} / \mathrm{HD}$ may experience comparable problems as to language. However, it is possible that this may be due to different aetiologies; like attention in children with $\mathrm{AD} / \mathrm{HD}$ and working memory in children with SLI. Thus a child with AD/HD may mix up words of similar meaning due to inattention when the words were first presented, while a child with SLI may show the same problem due to problems with working memory. In 
clinical contexts it would be of crucial importance to identify such problems in children with $\mathrm{AD} / \mathrm{HD}$ in order to develop effective treatment plans that are not exclusively verbally based. Overlooking language problems may negatively affect therapeutic outcome as well as school achievements. Thus professionals working with these children need to be aware of their language capabilities in order to help them resolve other difficulties (Cross, 2011).

Both clinical groups displayed equivalent levels of pragmatic difficulties and differed significantly from the TD children on the subscales measuring inappropriate initiation, stereotyped language, use of context and nonverbal communication as well as on the pragmatic composite. These findings underline that children with SLI may also experience substantial difficulties with pragmatics, although language structure and content might traditionally be the area of most concern. In line with this Bishop (2003) claimed that pragmatic difficulties may be overlooked or discounted if children present with poor structural language skills, and the presence of pragmatic problems may be more noticeable in children whose structural language skills are better. Furthermore, Whitehouse and colleagues (2009) reported pragmatic problems in adulthood in a follow up study of children identified with SLI without pragmatic impairments in childhood. They suggested that the pragmatic difficulties may have been overlooked in childhood and became apparent in more demanding and complex social situations in adulthood, alternatively that the pragmatic problems developed over time as secondary consequences of the initial structural language impairments. Our findings of the AD/HD group presenting with substantial pragmatic problems are also in line with previous research (Bishop \& Baird, 2001; Geurts et al., 2004).

The similarities found between the clinical groups on the subscale measuring social relations indicate that children with SLI experience problems comparable to children with $\mathrm{AD} / \mathrm{HD}$ regarding friendship and peer acceptance, this being a risk factor for the development of mental health problems. However, as pragmatic language abilities have shown to play an 
important role in social functioning and well- being, the pragmatic language impairments identified in both groups may contribute to the problems revealed on the social relation scale.

Regarding mental health problems our results showed that children with AD/HD experienced significantly more problems than children with SLI as measured by the SDQ. The groups differed on all subscales, except the one measuring pro-social behaviour, as well as on the total difficulties score and the impact score. Although SDQ data were not collected from the TD group, based on the norms presented in the scoring instructions (sdqscore.org) it is evident that children within both clinical groups present with major problems compared to typically developing children. However, it should be noted that in spite of their difficulties, almost half of the children in the SLI group were judged not to have problems to a degree that negatively interfered with the daily lives of their families. One may speculate what may cause this difference within the SLI group; it is possible that those not experiencing negative impact possess strengths, or protective factors, promoting positive developmental outcomes in the presence of risk factors (Fraser, 2004).

On the scale measuring hyperactivity-inattention the vast majority of the children in the AD/HD group, not unexpectedly, scored in the borderline/abnormal range, but a substantial portion of the children in the SLI group also scored in the same range. It is an interesting finding that second to the scale measuring peer problems, the hyperactivityinattention scale was the one in which most individuals in the SLI group scored in the borderline/abnormal range. This is in line with previous research pointing to symptoms of overlap between children with AD/HD and children with language impairments (Bruce et al., 2006; Tirosh \& Cohen, 1998). Peer problems were prominent in both groups and no significant difference was found between the $\mathrm{AD} / \mathrm{HD}$ group and the SLI regarding the frequency of children scoring in the borderline/abnormal range on this scale. It is possible that the reported peer problems may be due to the fact that language is of crucial importance for 
social interaction and that language impairments may lead the child to withdraw from social situations and place it at risk for social failure and peer rejection (Brinton \& Fujiki, 1993; Whitehouse et al., 2009). The reported peer problems on the SDQ are also consistent with the finding that both groups obtained a high score indicating problems on the scale measuring social relation on the CCC-2.

Some caution is needed when interpreting the results of the present study. The study focused on parental reports and did not include any objective measures obtained by standardized tests or other instruments. If the children had undergone individual assessments of language and mental health in addition, it is possible that a more nuanced picture would have appeared. Children with language impairments may have parents with similar problems and thus completing questionnaires may be linguistically demanding and put some parents at a disadvantage. It is a limitation to the study that diagnostic information regarding $\mathrm{AD} / \mathrm{HD}$ was based solely on parental information. It might have strengthened the study if teacher reports had been included as well as confirmed diagnosis by clinical psychologists or psychiatrists. Furthermore, no references to the children's general cognitive abilities other than parental reports may be an additional limitation to the study. However, Bishop and Baird (2001) reported that the parental pragmatic composite of the original CCC (Bishop, 1998) was not significantly related to verbal or nonverbal intellectual abilities. It could also be argued that the lack of information regarding socioeconomic status of the parents may affect the findings presented here. However, in Norway most residents have a relatively high standard of living. High employment rates combined with a universal social security system leads to few residents being poor compared to other European countries (Halvorsen \& Stjernø, 2008). The participants all lived in rural districts of Western Norway, and thus significant differences in socioeconomic status are not expected. As no "gold standard" exists, the criteria used for a diagnosis of SLI and the psychometric tests used may vary among the speech and language 
therapists who assessed the children. However, since the children were referred to a national support system of special education and diagnosed by specialized speech and language therapists it is plausible that they all displayed a significant level of language impairment.

The finding that the vast majority of the children in the AD/HD group displayed communication problems might be influenced by a possible selection bias although similar findings have been reported (Bruce et al., 2006). It was expected that all the children in the SLI group would have been identified as language impaired by the CCC-2. However, about one fifth of the children did not score within the clinical range. One possible explanation might be that some of the cases represent children whose language problems were resolved by the time the CCC-2 was completed. Due to lack of standardized language tests in Norwegian, another possibility is that some cases may be false positives because of imperfect reliability of the tests used as a basis for the diagnosis of SLI. Furthermore, this study reports data from relatively small samples and future larger -scale research is needed in order to obtain more knowledge about the research questions.

Children are usually diagnosed with either language difficulties or attention / behavioural difficulties, while they in fact may have both conditions. Our findings suggest that communication impairments are as prominent in children with $\mathrm{AD} / \mathrm{HD}$ as in children with SLI. However, the language profiles are not identical across groups; on two measures of language structure (speech and syntax) the SLI group is most impaired, while the picture is quite the opposite on a measure of interests. Mental health problems are common in both groups, but children in the $\mathrm{AD} / \mathrm{HD}$ group should experience significantly more problems than children in the SLI group according to all the SDQ scales. That children with SLI present with pragmatic problems comparable to those seen in children with $\mathrm{AD} / \mathrm{HD}$ should lead to therapeutic interventions also addressing pragmatics in addition to strategies directed towards language structure and content. 
Language profiles and mental health problems

In sum our findings underline the importance of assessing language in children with $\mathrm{AD} / \mathrm{HD}$ as well as including instruments sensitive to $\mathrm{AD} / \mathrm{HD}$ symptoms when assessing children with SLI. Furthermore, mental health problems should be an area of concern to be addressed in both groups as part of a standard assessment procedure. 


\section{References}

Adams, C. (2008). Intervention for children with pragmatic language impairments. In C.F. Norbury, J.B. Tomblin, \& D.V.M. Bishop (Eds.), Understanding developmental language disorders. From theory to practice. (pp. 189-204). New York: Psychology Press.

Adams, C., \& Lloyd, J. (2005). Elicited and spontaneous communicative functions and stability of conversational measures with children who have pragmatic language impairments. International Journal of Language and Communication Disorders, 40(3), 333-347.

Antoniazzi, D., Snow, P., \& Dickson-Swift, V. (2010). Teacher identification of children at risk for language impairment in the first years of school. International Journal of Speech-Language Pathology, 12(3), 244-252.

Beitchman, J. H., Brownlie, E. B., \& Wilson, B. (1996). Linguistic impairment and psychiatric disorder: pathways to outcome. In J. H. Beitchman, N. J. Cohen, M. M. Konstantareas \& R. Tannock (Eds.), Language, learning, and behavior disorder. Developmental, Biological, and Clinical Perspectives (pp. 493-514). Cambridge: University Press.

Beitchman, J. H., Wilson, B., Johnson, C. J., Atkinson, L., Young, A., Adlaf, E., et al. (2001). Fourteen-year follow-up of speech/language-impaired and control children: psychiatric outcome. Journal of the American Academy of Child and Adolescent Psychiatry, 40, 75-82.

Bignell, S., \& Cain, K. (2007). Pragmatic aspects of communication and language comprehension in groups of children differentiated by teacher ratings of inattention and hyperactivity. British Journal of Developmental Psychology, 25, 499-512. 
Bishop, D. V. M. (1998). Development of the Children's Communication Checklist (CCC): A method for assessing qualitative aspects of communicative impairment in children. Journal of Child Psychology and Psychiatry, 39(6), 879-891.

Bishop, D. V. M. (2003). The Children's Communication Checklist Second Edition (CCC-2). London: The Psychological Corporation.

Bishop, D. V. M., \& Baird, G. (2001). Parent and teacher report of pragmatic aspects of communication: use of the Children's Communication Checklist in a clinical setting. Developmental Medicine \& Child Neurology, 43, 809-818.

Bishop, D. V. M., \& McDonald, D. (2009). Identifying language impairment in children: combining language test scores with parental report. International Journal of Language and Communication Disorders, 44(5), 600-615.

Brinton, B, \& Fujiki, M. (1993). Language, social skills, and socioemotional behavior. Language, Speech and Hearing Services in Schools, 24, 194-198.

Bruce, B., Thernlund, G., \& Nettelbladt, U. (2006). ADHD and language impairment. A study of parent questionnaire FTF (Five to Fifteen). European Child and Adolescent Psychiatry, 15, 52-60.

Camarata, S. M., \& Gibson, T. (1999). Pragmatic language deficits in attention-deficit hyperactivity disorder (ADHD). Mental Retardation and Developmental Disabilities Research Reviews, 5, 207-214.

Cohen, J. (1988). Statistical power and analyses for the behavioral sciences. Hillsdale, NJ: Erlbaum.

Cohen, N. J., Vallance, D. D., Barwick, M., Im, N., Menna, R., Horodezky, N. B., et al. (2000). The interface between ADHD and language impairment: An examination of language, achievement, and cognitive processing. Journal of Child Psychology and Psychiatry, 41(3), 353-362. 
Cross, M. (2011). Children with social, emotional, and behavioural difficulties and communication problems. There is always a reason. London: Jessica Kingsley Publishers

Fraser, M.W. (2004). The ecology of childhood: A multisystems perspective. In M.W. Fraser (Ed), Risk and resilience in childhood. An ecological perspective (pp. 1-12). Washington DC: NASW Press.

Geurts, H. M., Vertè, S., Oosterlaan, J., Roeyers, H., Hartman, C. A., Mulder, E. J., et al. (2004). Can the Children's Communication Checklist differentiate between children with autism, children with ADHD and normal controls? Journal of Child Psychology and Psychiatry, 45(8), 1437-1453.

Geurts, M., \& Embrechts, M. (2008). Language Profiles in ASD, SLI and ADHD. Journal of Autism and Developmental Disorders, 38, 1931-1943.

Gillberg, C. (2010). The ESSENCE in child psychiatry: Early symptomatic syndromes eliciting neurodevelopmental clinical examination. Research in Developmental Disabilities, 31, 1543-1551.

Goodman, R. (1999). The extended version of the Strengths and Difficulties Questionnaire as a guide to child psychiatric caseness consequent burden Journal of Child Psychology and Psychiatry, 40), 791-799.

Halvorsen, K; \& Stjernø, S. (2008). Work, oil and welfare. Oslo, Norway: Universitetsforlaget.

Helland, W. A., Biringer, E., Helland, T., \& Heimann, M. (2010). Exploring language profiles for children with ADHD and children with Asperger syndrome. Journal of Attention Disorders. Online First, published on September 13, doi: 10.1177/1087054710378233

Helland, W. A., Biringer, E., Helland, T., \& Heimann, M. (2009). The usability of a Norwegian adaptation of the Children's Communication Checklist Second Edition 
(CCC-2) in differentiating between language impaired and non-language impaired 6-to 12-year-olds. Scandinavian Journal of Psychology, 50(287-292).

Helland, W.A., \& Heimann, M. (2007). Assessment of pragmatic language impairment in children referred to psychiatric services: A pilot study of the Children's Communication Checklist in a Norwegian sample. Logopedics Phoniatrics Vocology, $32,22-30$.

Helland, W. A., \& Møllerhaug, L. (2006). Sjekkliste for barns kommunikasjon 2 (CCC-2). Av D.V.M. Bishop. [The Children's Communication Checklist CCC-2 by D.V. M. Bishop]. Bergen, Norway: University of Bergen.

Hulme, C., \& Snowling, M. J. (2009). Developmental Disorders of Language Learning and Cognition. Singapore: Wiley- Blackwell.

Im-Bolter, N., \& Cohen, N. J. (2007). Language impairment and psychiatric comorbidities. Pediatric Clinics of North America, 54, 525-542.

Ketelaars, M. P., Cuperus, J., Jansonius, K., \& Verhoeven, L. (2010). Pragmatic language impairment and associated behavioural problems. International Journal of Language and Communication Disorders, 45(2), 204-214.

LaForett, D. R., Murray, D. W., \& Kollins, S. H. (2008). Psychosocial treatments for preschool-aged children with attention -deficit hyperactivity disorder. Developmental Disabilities Research Reviews, 14, 300-310.

Leonard, L. B. (1998). Children with specific language impairment. Cambridge: The MIT Press.

Luo, F., \& Timler, G.R. (2008). Narrative organization skills in children with attention deficit hyperactivity disorder and language impairment: application of the causal network model.Clinical Linguistic \& Phonetics, 22, 25-46. 
Mackie, L., \& Law, J. (2010). Pragmatic language and the child with emotional/behavioural difficulties (EDB): a pilot study exploring the interaction between behaviour and communication disability. International Journal of Language and Communication Disorders, 45(4), 397-410.

McInnes, A., Humphries, T., Hogg-Johnson, S., \& Tannock, R. (2003). Listening comprehension and working memory are impaired in attention-deficit-hyperactivity disorder irrespective of language impairment. Journal of Abnormal Child Psychology, $31(4), 427-443$.

Miniscalo, C., Nygren, G., Hagberg, B. S., Kadesjö, B., \& Gillberg, G. (2006). Neuropsychiatric and neurodevelopmental outcome of children at age 6 to 7 years who screened positive for language problems at 30 months. Developmental Medicine \& Child Neurology, 48, 361-366.

Muris, P., Meesters, C., \& van den Berg, F. (2003). The Strengths and Difficulties Questionnaire (SDQ). Further evidence for its reliability and validity in a community sample of Dutch children and adolescents. European Child and Adolescent Psychiatry, 12(1), 1-8.

Nelson, J. R., Benner, G. J., \& Cheney, D. (2005). An investigation of the language skills of students with emotional disturbance served in public school settings. The Journal of Special Education 39(2), 97-105.

Norbury, C. F., Tomblin, J. B., \& Bishop, D. V. M. (2008). A note on terminology. In Understanding language disorders. From theory to practice (pp. xiii-xv). Hove: Psychology press.

Obel, C., Heiervang, E., Rodriguez, A., Heyerdal, S., Smedje, H., Sourander, A., et al. (2004). The Strengths and Difficulties Questionnaire in the Nordic countries. European Child \& Adolescent Psychiatry, 13(2), II/33-II/ 39. 
Redmond, S.M., Thompson, H.L., \& Goldstein, S. (2011). Psycholinguistic profiling differentiates specific language impairment from typical development and from attention- deficit /hyperactivity disorder. Journal of Speech, Language and Hearing Research, 54, 99-117

Snowling, M. J., Bishop, D. V. M., Stothard, S. E., Chipchase, B., \& Kaplan, C. (2006). Psychosocial outcomes at 15 years of children with a preschool history of speechlanguage impairment. Journal of Child Psychology and Psychiatry, 47(8), 759-765.

Stackhouse, J. (2000). Barriers to literacy development in children with speech and language difficulties. In D. V. M. Bishop \& L. B. Leonard (Eds), Speech and language impairment in children: Causes, characteristics, intervention and outcome (pp. 7397). Hove: Psychology Press Ltd

Tirosh, E., \& Cohen, A. (1998). Language deficit with attention -deficit disorder: a prevalent comorbidity. Journal of Clinical Neurology, 13(10), 493-497.

Tomblin, J. B., Records, N. L., Buckwalter, P., Zhang, X., Smith, E., \& O'Brien, M. (1997). Prevalence of specific language impairment in kindergarten children. Journal of Speech, Language, and Hearing Research, 40, 1245-1260.

Toplak, M. E., Rucklidge, J. J., Hetherington, R., John, S. C. F., \& Tannock, R. (2003). Time perception deficits in attention-deficit/ hyperactivity disorder and comorbid reading difficulties in child and adolescent samples. Journal of Child Psychology and Psychiatry, 4(6), 888-903.

Whitehouse, A. J. O., Line, E. A., Watt, H. J., \& Bishop, D. V. M. (2009). Qualitative aspects of developmental language impairment relate to language and literacy outcome in adulthood. International Journal of Language and Communication Disorders, 44(4), 489-509. 
Language profiles and mental health problems

Will, J. W., \& Coufal, K. L. (2005). Emotional/Behavioral Disorders: A retrospective examination of social skills, linguistics, and student outcomes. Communication Disorders Quarterly, 27(1), 33-46.

Åsberg, J., Kopp, S., Berg-Kelly, K., \& Gillberg, C. (2010). Reading comprehension, word decoding and spelling in girls with autism spectrum disorders (ASD) and attentiondeficit/hyperactivity disorder (AD/HD): performance and predictors. International Journal of Language and Communication Disorders, 45(1), 61-71. 
Table 1: Means and standard deviations for CCC-2 raw scores (a high score indicates poor performance) for the three groups ${ }^{1}$

\begin{tabular}{|c|c|c|c|c|c|c|c|c|c|}
\hline \multirow{4}{*}{ Gender (male/female) } & \multicolumn{6}{|c|}{ Groups } & & & \\
\hline & \multicolumn{2}{|l|}{$\mathrm{TD}$} & \multicolumn{2}{|l|}{ ADHD } & \multicolumn{2}{|l|}{ SLI } & & & \\
\hline & \multicolumn{2}{|c|}{$17 / 2$} & \multicolumn{2}{|c|}{$17 / 4$} & \multicolumn{2}{|c|}{$17 / 2$} & \multicolumn{2}{|c|}{ Main effect } & \\
\hline & $\mathrm{M}$ & SD & $\mathrm{M}$ & $\mathrm{SD}$ & $\mathrm{M}$ & SD & $\mathrm{F}(2,56)=$ & $\eta^{2}$ & Post hoc \\
\hline A. Speech & 0.58 & 1.43 & 2.52 & 3.76 & 11.0 & 6.16 & $32.80^{* *}$ & .54 & $\mathrm{SLI}>\mathrm{TD}, \mathrm{ADHD} * *$ \\
\hline B. Syntax & 0.84 & 0.83 & 2.19 & 3.11 & 6.32 & 5.51 & $11.57 * *$ & .29 & $\mathrm{SLI}>\mathrm{TD}, \mathrm{ADHD} * *$ \\
\hline C. Semantics & 2.26 & 2.38 & 5.57 & 3.27 & 8.68 & 5.10 & $11.47 * *$ & .29 & SLI, ADHD > TD* \\
\hline D. Coherence & 1.89 & 1.76 & 6.57 & 4.57 & 7.42 & 4.56 & $11.22 * *$ & .29 & $\mathrm{SLI}, \mathrm{AD} / \mathrm{HD}>\mathrm{TD} * *$ \\
\hline E. Inappropriate initiation & 3.00 & 2.77 & 8.95 & 4.32 & 6.47 & 4.61 & $11.12 * *$ & .28 & $\mathrm{SLI}, \mathrm{AD} / \mathrm{HD}>\mathrm{TD} *$ \\
\hline F. Stereotyped language & 1.00 & 1.29 & 3.76 & 3.33 & 3.63 & 4.41 & $4.37 *$ & .14 & $\mathrm{SLI}, \mathrm{AD} / \mathrm{HD}>\mathrm{TD} *$ \\
\hline G. Use of context & 1.58 & 1.84 & 5.67 & 3.32 & 7.74 & 5.25 & $13.48 * *$ & .33 & $\mathrm{SLI}, \mathrm{AD} / \mathrm{HD}>\mathrm{TD} * *$ \\
\hline H. Nonverbal communication & 1.00 & 0.88 & 4.33 & 3.12 & 4.32 & 4.36 & $7.24 * *$ & .21 & $\mathrm{SLI}, \mathrm{AD} / \mathrm{HD}>\mathrm{TD} * *$ \\
\hline I. Social relations & 1.11 & 1.41 & 6.19 & 4.01 & 4.42 & 3.82 & $11.90 * *$ & .30 & $\mathrm{SLI}, \mathrm{AD} / \mathrm{HD}>\mathrm{TD} * *$ \\
\hline J. Interests & 2.16 & 1.71 & 7.52 & 3.74 & 4.32 & 3.53 & $14.75^{* *}$ & .35 & $\mathrm{AD} / \mathrm{HD}>\mathrm{TD}, \mathrm{SLI} * *$ \\
\hline
\end{tabular}

\footnotetext{
$* * p<.01 ; * p<.05 \quad{ }^{1}$ One -way analysis of variance
} 
Table 2: Means and standard deviations for SDQ- scales for the clinical groups ${ }^{1}$

A high score indicates impairment, except for the pro-social behaviour scale which is inverted

\begin{tabular}{|c|c|c|c|c|c|}
\hline & $\overline{\mathrm{ADHD}}$ & & $\overline{\text { SLI }}$ & & \\
\hline \multirow[t]{2}{*}{ Gender (male/female) } & \multicolumn{2}{|c|}{$17 / 2$} & \multicolumn{2}{|c|}{$17 / 4$} & \\
\hline & $\mathrm{M}$ & SD & $\mathrm{M}$ & SD & $p$ \\
\hline Emotional symptoms & 5.43 & 2.16 & 3.16 & 2.69 & * \\
\hline Conduct problems & 2.95 & 2.01 & 1.79 & 2.10 & $*$ \\
\hline Hyperactivity/inattention & 7.43 & 1.60 & 4.37 & 2.52 & $* *$ \\
\hline Peerproblems & 4.52 & 2.54 & 2.79 & 2.42 & $*$ \\
\hline Pro-social behaviour & 7.00 & 2.28 & 7.47 & 2.01 & $\mathrm{~ns}$ \\
\hline Total difficulties & 20.33 & 5.09 & 12.21 & 7.63 & $* *$ \\
\hline Impact & 4.35 & 2.96 & 2.05 & 2.74 & $* *$ \\
\hline
\end{tabular}

\footnotetext{
$*^{* *} p<.01 ; * p<.05 ;$ Mann-Whitney $U$-test, two-tailed.
} 
Table 3: Percentage (N) of children in the clinical groups scoring in the abnormal / borderline range on the SDQ according to U.K norms

\begin{tabular}{lccc}
\hline & ADHD & SLI & \\
\hline & $\%$ abnormal / & & \\
& borderline & abnormal / & \\
& $81.0(17)$ & borderline & $*$ \\
\hline Emotional symptoms & $38.1(8)$ & $31.6(6)$ & ns \\
Conduct problems & $85.7(18)$ & $21.1(4)$ & $*$ \\
Hyperactivity/inattention & $76.2(16)$ & $42.1(8)$ & $\mathrm{ns}$ \\
Peerproblems & $23.8(5)$ & $57.9(11)$ & $\mathrm{ns}$ \\
Pro-social behaviour & $90.5(19)$ & $31.6(6)$ & $*$ \\
Total difficulties & $85.7(18)$ & $52.6(10)$ & $*$ \\
Impact & & & \\
\hline
\end{tabular}

$* p<.05$; Mann-Whitney $U$-test, two-tailed. 